\title{
PRÁTICAS DE GOVERNANÇA CORPORATIVA DAS COMPANHIAS BRASILEIRAS OPERADAS NA BOLSA DE VALORES DE NOVA IORQUE
}

\author{
BOTELHO, Luciano Henrique Fialho ${ }^{1}$ \\ SILVA, Thaís Santos ${ }^{2}$ \\ MARQUES, Humberto Rodrigues ${ }^{1}$ \\ PEREIRA, Rafael Morais ${ }^{1}$ \\ COSTA, Thiago de Melo Teixeira $\mathrm{da}^{3}$
}

\begin{abstract}
RESUMO: O mercado de capitais brasileiro obteve avanços nos últimos anos, a partir da criação de normas mais eficazes de Governança Corporativa. No entanto, esse mercado ainda é pouco expressivo no país, diferentemente do que ocorre nos países desenvolvidos. Por esse motivo, com o alicerce da globalização financeira, muitas empresas brasileiras buscam recursos em bolsas de valores estrangeiras, principalmente na Bolsa de Valores de Nova York, possuidora de regras reduzidas para empresas estrangeiras. Esse artigo tem como objetivo analisar ações de Governança Corporativa praticadas pelas empresas brasileiras atuantes na NYSE, numa perspectiva comparada com as regras da bolsa norte-americana. A Governança Corporativa é destacada a partir de suas particularidades no Brasil e na NYSE e de aspectos envolvidos, como a transparência. De modo a atingir os objetivos propostos, foi utilizada uma abordagem predominantemente qualitativa, descritiva e com tratamento de dados através de pesquisa documental. Os resultados foram encontrados através da análise de Relatórios contendo exigências que as empresas estrangeiras devem seguir para atuar na NYSE. Os resultados demonstraram que nem todas as exigências da NYSE para as empresas norte-americanas são desenvolvidas pelas empresas brasileiras, sendo esse não seguimento de normas justificado pela não exigências nas regras brasileiras.
\end{abstract}

Palavras-chave: Governança corporativa. Exigências. NYSE.

SUMMARY: The Brazilian capital market made progress in recent years, from developing more effective standards of Corporate Governance. However, this market is still very expressive in the country, unlike what happens in developed countries. Therefore, with the foundation of financial globalization, many Brazilian companies seeking resources in foreign stock exchanges, primarily in the New York Stock Exchange, which exhibited reduced rules for foreign companies. This article aims to analyze actions of corporate governance practiced by the leading Brazilian companies on the NYSE, in a comparative perspective with the rules of the U.S. exchange. Corporate Governance is detached from its particularities in Brazil and the NYSE and involved aspects such as transparency. In order to achieve the proposed objectives, a predominantly qualitative, descriptive and processing of data through documentary research approach was used. The results were found by analyzing reports containing requirements that foreign companies must follow to act on the NYSE. The results showed that not all the requirements of the NYSE for U.S. companies are developed by Brazilian companies, this is not justified by the following rules are no requirements in Brazilian rules.

Keywords: Corporate Governance. Requeriments. NYSE.

RESUMEN: El mercado de valores de Brasil avanzó en los últimos años, desde la creación de normas más eficaces de gobierno corporativo. Sin embargo, este mercado todavía no es muy significativa en el país, a diferencia de lo que ocurre en los países desarrollados. Por esta razón, con la fundación de la globalización financiera, muchas empresas brasileñas buscan otorga recursos de valores extranjeros, principalmente en la Bolsa de Valores de Nueva York, que poseen reglas reducidos para las empresas extranjeras. Este artículo tiene como objetivo analizar las acciones de gobierno corporativo practicado por empresas brasileñas activas en la Bolsa de Nueva York, en una perspectiva comparada con las normas del mercado de valores de Estados Unidos. El gobierno corporativo se separa de sus peculiaridades en Brasil y NYSE y aspectos involucrados, como la transparencia. Con el fin de alcanzar los

\footnotetext{
${ }^{1}$ Mestrando em Administração - Departamento de Administração e Contabilidade - Universidade Federal de Viçosa

${ }^{2}$ Mestranda em Administração - Universidade Federal de Minas Gerais

${ }^{3}$ Professor orientador - Departamento de Administração e Contabilidade - Universidade Federal de Viçosa
} 
objetivos propuestos, un enfoque predominantemente cualitativo, descriptivo y el procesamiento de datos a través de la investigación documental se utilizó. Se encontró que los resultados a través del análisis de los informes que contienen los requisitos que las empresas extranjeras deben seguir para actuar en el NYSE. Los resultados mostraron que no todos los requisitos de la NYSE para las compañías estadounidenses son desarrollados por empresas brasileñas, y esto no se siguen las normas no justificados por necesidades de normas brasileñas.

Palabras clave: Gobierno corporativo. Requisitos. NYSE.

\section{INTRODUÇÃO}

O mercado de capitais brasileiro vem obtendo alguns avanços, como alterações na Lei das Sociedades Anônimas, alicerçando normas mais eficazes de governança corporativa e da concepção de um sistema de pagamentos (SPB) mais novo. Contudo, mesmo com um potencial de crescimento reconhecido globalmente, o mercado de capitais no país, ainda, é pouco expressivo, diferentemente do que ocorre nos países que foram bem articulados em seu processo de desenvolvimento. Nesse sentido, quando enfatizado o mercado acionário do país, o que se verifica são poucas empresas listadas quando comparado a outros mercados, implicando numa necessidade de atrair mais empresas e investidores e, consequentemente, contribuir para o desenvolvimento nacional.

Nessa perspectiva, Medeiros e Tibério (2009), apontam que mercados de capitais pequenos ou pouco desenvolvidos são um dos fatores que motivam as empresas a listarem suas ações em bolsas de valores estrangeiras. Os mesmos autores salientam também outros motivos, como o marketing, na medida em que investir em mercados estrangeiros traz maior visibilidade para a empresa, e o financeiro, na busca de financiamento mais barato ou mais facilmente disponível. Além disso, empresas de determinados setores se mostram mais propensas a buscar o mercado internacional, como apresentado por Pagano et al. (2001), que após estudar empresas antes e após a adesão em bolsas estrangeiras, verificaram que companhias de alta tecnologia e aquelas com forte orientação para a exportação são mais atraídas para as bolsas norte-americanas.

Essa tendência de listagem em bolsas estrangeiras tornou-se possível nos tempos atuais devido à globalização financeira, esse conceito constitui-se pela interligação de mercados de capitais em escala mundial, dessa maneira, forma-se um mercado unificado de investimentos e captação de recursos, sem fronteira para os investidores (PLIHON, 2007). Com relação às companhias brasileiras, essa tendência tem se confirmado, especificamente, em relação à Bolsa de Valores de Nova York (NYSE), sendo que o Brasil foi, em 2012, o país estrangeiro com maior volume de transações negociadas na NYSE, superando alguns países da Europa, o Canadá e a China (JÚNIOR, 2012). Essa internacionalização ocorre devido ao ganho de liquidez com o acesso a novos investidores, principalmente norte-americanos, que apresentam um perfil diferente dos brasileiros. Os norte-americanos são mais arrojados, pois "o hábito de investir na bolsa de valores é disseminado desde cedo na população, o resultado disso é que na bolsa de valores norteamericana, 70\% dos investidores são pessoas físicas" (ESCAVASSA, 2008, p. 69). Já no Brasil, a poupança é o produto financeiro preferencial, em termos de investimento, o que caracteriza um perfil mais conservador do brasileiro em termos de adesão ao risco, ainda, os juros elevados praticados no Brasil tornam a renda fixa um investimento bastante rentável, minimizando a entrada de investidores na renda variável.

Nesse processo de atuação de companhias brasileiras em bolsas de valores no exterior, faz-se necessário que essas empresas se adéquem a diversos fatores, dentre os quais se destaca a adoção de práticas de governança corporativa. Como identificado nos estudos de Medeiros e Tibério (2009), comparada com outras variáveis, a governança corporativa representou um nível de maior significância 
com relação à importância para que uma empresa se insira em mercados de capitais estrangeiros. O termo governança corporativa, que vem sendo explorado nas últimas décadas, pode ser entendido como um conjunto de práticas adotadas pelas empresas, visando à proteção dos acionistas no mercado de capitais e, consequentemente, um aumento no seu valor de mercado.

Considerando um escopo mais abrangente, a temática da governança corporativa envolve diversos fatores, como a estrutura de propriedade, a remuneração dos dirigentes, a composição do Conselho de Administração, a proteção dos minoritários, além da transparência (CORREIA et al, 2011). Diante disso, para que as empresas sejam listadas na NYSE, uma das mais importantes bolsas de valores do mundo, elas devem considerar diversos aspectos de governança, evidenciados pela Lei Sarbanes-Oxley e pelas normas da própria NYSE. Dentre os principais fatores estão a implantação de comitês nas companhias, como comitês de auditoria, e o envio à NYSE de declarações, anuais ou intermediárias, que remetem às regras de governança corporativa.

Entretanto, verifica-se que a NYSE aplica um número reduzido de regras de governança corporativa a empresas estrangeiras, em relação às companhias de origem norte americanas, o que vem justificando a evolução de empresas brasileiras listadas na bolsa norte-americana. Ressalta-se, assim, o potencial apresentado pelas companhias brasileiras nesse processo, visto que o Brasil já adota políticas que incentivam o movimento de governança corporativa. Nessa perspectiva, destacam-se as atuações do Instituto Brasileiro de Governança Corporativa (IBGC), que desenvolveu o código brasileiro de governança corporativa em 1999, e da Bolsa de Valores, Mercadorias e Futuros de São Paulo (BM\&FBOVESPA), que estabeleceu níveis diferenciados, de acordo com as práticas de governança desenvolvidas pelas empresas.

Portanto, considerando como base o fenômeno da internacionalização do mercado de capitais, principalmente, a atratividade da NYSE, e o incentivo recente, por parte do Brasil, para que as empresas nacionais adotem práticas de governança corporativa, indagou-se, como as companhias brasileiras listadas na NYSE se posicionam, em termos de governança corporativa, quando comparadas às exigências da bolsa norte-americana? A fim de responder a esse questionamento, esse artigo teve como objetivo, analisar ações de governança corporativa praticadas pelas companhias brasileiras atuantes na NYSE, numa perspectiva comparada com as regras da bolsa norte-americana.

Para tanto, define-se como objetivos intermediários mapear as companhias brasileiras listadas na NYSE, considerando variáveis, como o ano de ingresso, segmento de atuação e nível de governança na BM\&FBOVESPA e ponderar práticas de governança adotadas pelas empresas brasileiras e compará-las com as exigências da bolsa norte-americana.

Nas duas seções seguintes, apresenta-se a fundamentação teórica utilizada, englobando o contexto atual de globalização financeira, situando o mercado de capitais brasileiro, e os principais conceitos referentes à governança corporativa, destacando os regulamentos de governança da BM\&FBOVESPA e da NYSE.

\section{GLOBALIZAÇÃO FINANCEIRA: INTEGRAÇÃO DE MERCADOS DE CAPITAIS E AS BOLSAS DE VALORES}

O advento da abertura econômica em uma época de grande crescimento do capitalismo, o desenvolvimento de novas tecnologias de informação e comunicação (TIC's), que simplificaram o processo de se relacionar em longas distâncias, e a evolução demográfica ocorrida após a segunda guerra mundial, contribuíram para a globalização financeira. No entanto, no Brasil, a internacionalização 
financeira só evoluiu a partir da década de 90, quando ocorreram algumas desregulamentações na economia nacional (PLIHON, 2007).

De acordo com Plihon (2007) a globalização financeira constitui-se na interligação de mercados de capitais em escala global, resultando no surgimento de um mercado unificado de investimentos e captação de recursos. Assim, através dessa quebra de fronteiras, investidores residentes em vários países podem adquirir produtos financeiros localizados em países diferentes do seu, auferindo melhores rendimentos e oferecendo a empresas de outros países recursos essenciais, esse fenômeno é denominado cross-listing na literatura financeira (MEDEIROS; TIBÉRIO, 2009).

Para Assaf Neto (2006), corroborando com a visão econômica tradicional, a captação de recursos no exterior é uma possibilidade para as organizações brasileiras, tendo em vista sistemas menos burocráticos, gerando rapidez nas operações, uma maior liquidez e, ainda, grande demanda externa. Ademais, ao abrir capital no exterior as empresas veem a possibilidade de ganhar vantagens competitivas e maiores recursos para a suas estratégias. Saudagaran (1988) apud Medeiros e Tibério (2009) estudou os fatores que levam as organizações a listarem suas ações em outros países, a partir de quatro vertentes das organizações, conforme demonstra o Quadro 1.

Quadro 1: Vantagens de se abrir capital no exterior.

\begin{tabular}{|c|c|}
\hline Financeiro & $\begin{array}{c}\text { Expandir a base de potenciais investidores, aumentar a demanda por suas ações, } \\
\text { elevando a sua liquidez. }\end{array}$ \\
\hline Marketing & Aumento da visibilidade organizacional \\
\hline $\begin{array}{c}\text { Recursos } \\
\text { Humanos }\end{array}$ & $\begin{array}{c}\text { Empresas com funcionários no exterior poderiam remunerá-los com ações como forma } \\
\text { de incentivo }\end{array}$ \\
\hline Políticas & Apoios internacionais \\
\hline
\end{tabular}

Fonte: Adaptado Medeiros e Tibério (2009).

Além disso, esses autores ressaltam que determinados setores da economia têm mais propensão para a atuação no exterior, como os setores de Papel e Celulose e de Telecomunicações, pois refletem uma indústria de caráter fortemente exportador, no primeiro caso, e uma de alta tecnologia, no segundo (MEDEIROS; TIBÉRIO, 2009). Ainda, apontaram que, apesar de avanços notáveis, o mercado brasileiro ainda não é desenvolvido, favorecendo as empresas brasileiras a listarem suas ações em bolsas de valores externas.

Um dos principais destinos das empresas brasileiras que buscam recursos no exterior é a bolsa de valores de Nova York (NYSE). Essa surgiu no século XVIII e é considerada a maior bolsa de valores do mundo, o que pode ser explicado pela liderança econômica que os Estados Unidos da América (EUA) exerce no cenário internacional. Ressalta-se que há um ganho para as empresas brasileiras na NYSE, devido à adoção, por parte dessas empresas, dos padrões internacionais nos relatórios contábeis, dessa forma, adequam-se à contabilidade global, favorecendo suas atividades internacionais (OLIVEIRA; LEMES, 2011).

Com relação às dificuldades da bolsa de valores brasileira, Pereira (2012) enfatiza a volatilidade e o baixo nível de investimento dos brasileiros na bolsa, com apenas $0,6 \%$ da população, nível muito baixo em comparação com os $92 \%$ dos americanos que investem no mercado de capitais local, evidenciando que os brasileiros ainda optam por aplicar seus recursos na poupança. Para Furlan (2013), a falta de governança política, o medo das pessoas físicas, caracterizado pela participação de apenas 15,86\% em 2013 na BM\&FBOVESPA, e, principalmente, as altas taxas de juros brasileiras, penalizam a bolsa nacional. 
Tendo em vista tais problemas e a crescente preocupação dos investidores com a governança corporativa, a antiga Bolsa de Valores de São Paulo (BOVESPA) criou níveis diferenciados para incentivar a governança corporativa. Esses, aliados à estabilização da economia, com o maior acesso ao capital estrangeiro, contribuíram para o crescimento da bolsa nacional, apesar dessa ainda sofrer com dificuldades, principalmente aquelas relacionadas à assimetria de informação, que ainda afeta a eficiência do mercado de capitais brasileiro (NETO; FAMÁ, 2001). Na seção seguinte são apresentadas as principais considerações acerca da governança corporativa, destacando as práticas exigidas no âmbito da BM\&FBOVESPA e da NYSE.

\section{GOVERNANÇA CORPORATIVA}

O conceito de governança corporativa surgiu no início da década de 1990, na Europa e nos EUA. No Brasil esse tema é relativamente novo, e ainda possui vários campos de estudos a serem explorados (GARCIA, 2005). Assume-se governança corporativa como um conjunto de princípios que procuram reduzir potenciais conflitos de interesse entre acionistas controladores e minoritários, bem como entre os demais influenciados pela organização, visando maximizar o valor da empresa (ANDRADE; ANDRADE, 2005). Assim, o cerne para a criação da governança corporativa foram os problemas descritos pela teoria de agência. Tal pressuposto, "consiste em um contrato onde uma ou mais pessoas (o principal) engajam outra pessoa (o agente) para desempenhar alguma tarefa em seu favor, envolvendo delegação de autoridade para a tomada de decisão pelo agente" (JENSEN; MECKLING, 1976. p. 5).

Destarte, torna-se relevante estudar a temática da governança corporativa, que no escopo mais abrangente envolve fatores como, a estrutura de propriedade, a remuneração dos dirigentes, a composição do Conselho de Administração, a proteção dos minoritários, além da transparência (CORREIA et al., 2011). Vários autores estudaram esses aspectos relacionando-os à governança corporativa, ainda, outros princípios também são destacados por estudiosos para a finalidade da governança corporativa, como transparência na gestão (BARBOSA, 2012; SROUR, 2005; RODRIGUES, 2003), políticas de remuneração (ODA, 2009; MOTTA; SILVEIRA; BORGES, 2006), comitê de auditoria (OLIVEIRA; COSTA, 2005; SANTOS, 2009), equidade (LISOT, 2012; GARCIA; 2005; PITZER, 2011), accountability (GARCIA, 2005; GONÇALVES et al., 2008), entre outros.

No cenário brasileiro, a primeira ação relacionada à temática foi o desenvolvimento do código brasileiro sobre governança corporativa, publicado em 1999 pelo IBGC, com algumas revisões posteriormente. Além disso, como mencionado anteriormente, a antiga BOVESPA criou níveis diferenciados de governança corporativa, incentivando essa prática nas companhias brasileiras. Colombo e Galli (2010) enfatizam que ao criar três níveis de governança corporativa, a BOVESPA desenvolveu o Nível I, como um nível de reduzidas regras e menor comprometimento, já o Nível 2, como intermediário, e o Novo Mercado com o segmento em que as organizações adotam $100 \%$ das regras de governança corporativa. De acordo com Berk e Demarco (2009) apud Basso (2011), para as organizações, a adesão aos segmentos diferenciados, supracitados, reduz os riscos dos investidores, nelas interessados, pela aplicação de boas práticas de governança na administração.

$\mathrm{O}$ regulamento exige que, a partir da assinatura do contrato entre a BM\&FBOVESPA e a companhia, para entrada no segmento Nível 1, a empresa passa a ter compromissos com relação aos investidores, como o fornecimento de informações que auxiliam na avaliação do valor da empresa, além de se comprometerem a divulgar para os acionistas todos os acordos firmados com terceiros. No que concerne à passagem para o segmento Nível 2, a empresa precisa atender às exigências do Nível 1, além 
de outras práticas de governança corporativa, como conferir direito de voto restrito aos acionistas preferenciais em situações de fusões e de aprovações de contratos entre a organização e o seu controlador (BM\&FBOVESPA, 2014).

Como último segmento de listagem, surgiu, em 2000, o Novo Mercado, que para Carvalho (2002), foi o marco inicial de uma nova fase do mercado de capitais brasileiro, onde o setor privado passa a liderar processos na realização de reformas, assim, garante-se agilidade e competência aos recursos dos investidores. $\mathrm{O}$ autor reitera também que a não obrigatoriedade legal, mas contratual do Novo Mercado apresenta uma forma de ganho de vantagem competitiva às organizações que o aderem (CARVALHO, 2002). Em relação às obrigações desse nível, mantêm-se toda a regulamentação do Nível 2, além de ser exigido que as organizações possuam no mercado apenas ações ordinárias, sendo o voto realizado de forma direta.

Com a criação de níveis de diferenciação e o crescimento do Novo Mercado, ocorreu à expansão do mercado de capitais e, consequentemente, um aumento significativo também nos valores que giram na bolsa brasileira. Durante a primeira década do século XXI, os valores praticados chegaram acerca de $\mathrm{R} \$ 1,3$ trilhões, em 2009, com uma valorização de 562,5\% de 2001 a 2010 (COLOMBO; GALLI, 2010).

Já no contexto da NYSE, as práticas exigidas de governança corporativa sobre as companhias de capital aberto são mais rigorosas, visto que já houve um amadurecimento dessa temática no âmbito norteamericano. Contudo, visando atrair empresas estrangeiras, a NYSE exige das companhias não americanas o cumprimento de um número reduzido de normas relativas à governança corporativa. Dentre as quais estão as exigências previstas na Exchange Act Rule 10A-3, sobre comitês de auditoria, envio de comunicados e relatórios da companhia à NYSE, assim como, uma listagem comparativa entre as práticas adotadas pela companhia e aquelas verificadas nas empresas norte-americanas. Esse último critério compreende nove exigências, que serão apresentadas na seção seguinte.

\section{AS PRÁTICAS DE GOVERNANÇA CORPORATIVA EXIGIDAS PELA NYSE}

A NYSE, através das suas regras para empresas não americanas, determina que as mesmas façam um relatório contendo uma comparação entre suas práticas de governança e as práticas das empresas americanas. São destacadas nesse relatório a existência de conselhos independentes, sessões executivas, comitê de governança corporativa, comitê de remuneração, comitê de compensação, comitê de auditória, diretrizes de governança, código de ética e declaração de não violação as regras da NYSE. Esse relatório recebe o nome de Relatório 20-F, ele é enviado anualmente à NYSE e disponibilizado eletronicamente pelas empresas. A seguir, no quadro 2, são abordadas as principais conceituações e características sobre dessas nove exigências, a partir das definições de vários estudiosos dessa área.

Quadro 2: empresas estrangeiras e as exigências da NYSE

(Continua)

\begin{tabular}{|c|l|}
\hline Exigências & \multicolumn{1}{c|}{ Descrições } \\
\hline $\begin{array}{c}\text { Conselhos } \\
\text { Independentes }\end{array}$ & $\begin{array}{l}\text { São missões desses conselhos independentes a definição da estratégia, a } \\
\text { eleição e destituição do executivo principal (CEO), além da aprovação do } \\
\text { desígnio dos demais executivos por proposta do CEO o o acompanhamento } \\
\text { da gestão e luta pelo interesse dos acionistas (GONDRIGE; CLEMENTE; } \\
\text { ESPEJO, 2012). O Conselho de Administração deve apresentar estratégias, } \\
\text { eleger os principais, além de avaliar o desempenho da gestão (MERAT, } \\
\text { 2011). }\end{array}$ \\
\hline Sessões Executivas & $\begin{array}{l}\text { Reunião do Conselho de Administração sem que haja a presença dos } \\
\text { membros referentes à diretoria (NYSE, 2013). Torna-se relevante em evitar } \\
\text { os julgamentos independentes sobre a empresa realizados por esses não } \\
\text { executivos (ANDRADE; ROSSETI, 2006). }\end{array}$ \\
\hline
\end{tabular}

Nucleus,v.13,n.1,abr.2016 
Quadro 2: empresas estrangeiras e as exigências da NYSE

(Conclusão)

\begin{tabular}{|c|c|}
\hline Exigências & Descrições \\
\hline $\begin{array}{c}\text { Comitê de Governança } \\
\text { Corporativa }\end{array}$ & $\begin{array}{l}\text { Aborda aspectos como as responsabilidades do diretor presidente e a } \\
\text { disponibilização de práticas de governança em seus websites (NYSE, 2013). } \\
\text { Nesse sentido, a adoção de tal comitê favorece para que os investidores } \\
\text { exercem cada vez mais pressão para existência de normas de transparência } \\
\text { nas ações das companhias (LETHBRIDGE, 1997). }\end{array}$ \\
\hline $\begin{array}{c}\text { Comitê de } \\
\text { Remuneração }\end{array}$ & $\begin{array}{l}\text { Comitê composto por conselheiros independentes, pautados por um } \\
\text { regimento interno que especifique seus deveres mínimos (NYSE, 2013). } \\
\text { Constitui-se importante na valorização de todos os Stakeholders, priorizando } \\
\text { o controle e a transparência como proteção institucional (BARBOSA, 2012). }\end{array}$ \\
\hline Comitê de Auditória & $\begin{array}{l}\text { Formado por no mínimo três conselheiros independentes regidos por um } \\
\text { regulamento interno que especifique os deveres mínimos (NYSE, 2013). } \\
\text { Fornecimento de apoia à administração no que diz respeito a contabilidade e } \\
\text { finanças (OLIVEIRA; COSTA, 2005). }\end{array}$ \\
\hline $\begin{array}{c}\text { Planos de } \\
\text { Remuneração por } \\
\text { Ações }\end{array}$ & $\begin{array}{l}\text { Os acionistas possuem o direito de voto sobre todos os planos de } \\
\text { remuneração mediante oferta de participação no capital da companhia, bem } \\
\text { como as alterações dos mesmos (NYSE, 2013). Apesar de ser considerada } \\
\text { uma ferramenta importante, esse programa ainda não é comum para a maioria } \\
\text { das empresas listadas no novo mercado da BM\&FBOVESPA (SILVA; } \\
\text { SANTOS, 2009). }\end{array}$ \\
\hline $\begin{array}{l}\text { Diretrizes de } \\
\text { Governança }\end{array}$ & $\begin{array}{l}\text { Determina a divulgação e adoção de diretriz de governança sobre certos } \\
\text { requisitos mínimos especificados pela NYSE (BORGERTH, 2011). Esses } \\
\text { diretrizes relatam questões como os encargos do diretor presidente e a } \\
\text { disponibilização de práticas de governança em seus websites (NYSE, 2013). }\end{array}$ \\
\hline Código de Ética & $\begin{array}{l}\text { Para Silva (2007), o código de conduta e ética permite que a companhia trace } \\
\text { diretrizes claras e fomentarem o diálogo com seus diversos públicos. } \\
\text { Importante para as ações da organização e na divulgação de informação } \\
\text { (NYSE, 2013). }\end{array}$ \\
\hline $\begin{array}{c}\text { Declaração de não } \\
\text { violação a regras da } \\
\text { NYSE }\end{array}$ & $\begin{array}{l}\text { As companhias devem, a partir de seu CEO, declarar anualmente à bolsa } \\
\text { americana que não tem conhecimento de infrações cometidas pela companhia } \\
\text { contra as regras de governança corporativa descritas pela mesma (NYSE, } \\
\text { 2103). }\end{array}$ \\
\hline
\end{tabular}

Fonte: Elaborado com base nos autores mencionados.

A partir das bases apresentadas nesse capítulo, na próxima seção estão os procedimentos metodológicos utilizados para a consecução dos objetivos propostos neste artigo.

\section{PROCEDIMENTOS METODOLÓGICOS}

O presente artigo teve como objetivo principal analisar ações de governança corporativa praticadas pelas companhias brasileiras atuantes na NYSE, numa perspectiva comparada com a legislação norte-americana. Desse modo, a fim de atingir o objetivo proposto foi utilizada uma abordagem predominantemente qualitativa, pois essa vertente, segundo Vieira (2006, p. 18), "oferece descrições ricas e bem fundamentadas, além de explicações sobres processos em contextos locais identificáveis". Quanto ao objetivo, adotou uma perspectiva descritiva, uma vez que se propões a enumerar, comparativamente, práticas de governança adotadas pelas companhias em estudo.

Quanto aos meios, tratou-se de uma pesquisa documental, caracterizada por Neves (1996, p. 03) como o "exame de materiais que ainda não receberam um tratamento analítico ou que podem ser reexaminados com vistas a uma interpretação nova ou complementar". Os dados foram coletados a partir 
dos Relatórios 20-F das empresas estudadas, que são enviados anualmente à NYSE e disponibilizados eletronicamente pelas empresas. As unidades de análise deste estudo correspondem às companhias brasileiras atuantes na NYSE, totalizando 27 empresas, em maio de 2014, como apresentado no quadro a seguir (Quadro 3).

Quadro 3: Empresas brasileiras listadas na NYSE.

\begin{tabular}{|c|c|c|c|}
\hline Companhia & Símbolo & Companhia & Símbolo \\
\hline $\begin{array}{l}\text { Ambev - Companhia de Bebidas das } \\
\text { Américas }\end{array}$ & $\mathrm{ABV}$ & Embraer S.A. & ERJ \\
\hline Banco Bradesco, S.A. & BBD & Fibria Celulose S.A. & FBR \\
\hline Banco Santander (Brasil) S.A. & BSBR & Gafisa S.A. & GFA \\
\hline Brasil Telecom S.A. (OI S.A.) & BTM & Gerdau S.A. & GGB \\
\hline Braskem S.A. & BAK & $\begin{array}{l}\text { GOL Linhas Aéreas Inteligentes } \\
\text { S.A. }\end{array}$ & GOL \\
\hline BRF - Brasil Foods S.A. & BRFS & Itaú Unibanco Holding S.A. & ITUB \\
\hline $\begin{array}{l}\text { Centrais Elétricas Brasileiras S.A. - } \\
\text { Eletrobrás }\end{array}$ & EBR & Petrobras - Petróleo Brasileiro S.A. & PBR \\
\hline $\begin{array}{l}\text { Companhia Brasileira de } \\
\text { Distribuição }\end{array}$ & CBD & TAM S.A. & TAM \\
\hline $\begin{array}{l}\text { Companhia de Saneamento Básico } \\
\text { do Estado de São Paulo-SABESP }\end{array}$ & SBS & Tele Norte Leste Participações S.A. & TNE \\
\hline $\begin{array}{l}\text { Companhia Energética de Minas } \\
\text { Gerais - CEMIG }\end{array}$ & CIG & $\begin{array}{l}\text { Telecomunicações de São Paulo } \\
\text { S/A -Telesp }\end{array}$ & VIVWI \\
\hline $\begin{array}{l}\text { Companhia Paranaense de Energia } \\
\text { (COPEL) }\end{array}$ & ELP & Telefônica Brasil, S.A. & VIV \\
\hline Companhia Siderúrgica Nacional & SID & Tim Participações S.A. & TSU \\
\hline Cosan Limited & $\mathrm{CZZ}$ & \multirow{2}{*}{ Vale S.A. } & \multirow{2}{*}{ VALE } \\
\hline CPFL Energia S.A. & $\mathrm{CPL}$ & & \\
\hline
\end{tabular}

Fonte: NYSE, Adaptado pelos autores.

Dentre as 27 empresas listadas, foram analisadas neste artigo apenas 24 , sendo desconsideradas a Tele Norte Leste Participações S.A. (TNE), por indisponibilidade de informações pela empresa e por sua incorporação à Brasil Telecom S.A. (OI S.A.), a Telecomunicações de São Paulo S/A (Telesp), que foi incorporada pela Telefônica Brasil S.A. e a TAM S.A., que após a sua fusão com a empresa LAN, não opera mais na BM\&FBOVESPA e tem sua origem registrada na NYSE como norte-americana.

A análise dos dados se sustentou por meio do referencial teórico utilizado, sendo estruturada a partir dos objetivos intermediários propostos. Primeiramente, disserta-se sobre o processo de entrada das companhias brasileiras na NYSE, considerando algumas variáveis, como ano de ingresso, segmento de atuação e nível de governança na BM\&FBOVESPA. Por fim, realizou-se a análise da governança corporativa das companhias em questão, considerando as exigências norte-americanas em relação aos fatores: conselheiros independentes, sessões executivas, comitê de governança corporativa, comitê de compensação, comitê de auditoria, planos de remuneração por ações, diretrizes de governança corporativa, código de ética e declarações dos Diretores Presidentes à NYSE.

\section{MAPEAMENTO DAS COMPANHIAS BRASILEIRAS LISTADAS NA NYSE}

$\mathrm{Na}$ perspectiva da globalização financeira, verifica-se que as empresas brasileiras visualizaram nos mercados estrangeiros uma forma de atuarem e expandirem seus negócios e captação de recursos. Os EUA, por possuir uma economia mais desenvolvida atraiu muitas dessas empresas, sendo que, como 
verificado na Figura 1, a partir de 1997, houve um aumento de empresas brasileiras listadas NYSE, uma vez que foi nessa década que o governo atou na desregulamentação para que essas empresas pudessem operar em mercados estrangeiros (PLIHON, 2007). Saudagaran (1988) apud Medeiros e Tibério (2009) explicam que esse aumento da expansão das empresas em mercados estrangeiros, é resultante da busca por tecnologia, matéria-prima, capital intelectual e financeiro em outros países, uma vez que os dinâmicos processos de globalização proporcionam a essas organizações um potencial de crescimento em países internacionais.

Figura 1 - Evolução das empresas brasileiras listadas na NYSE.

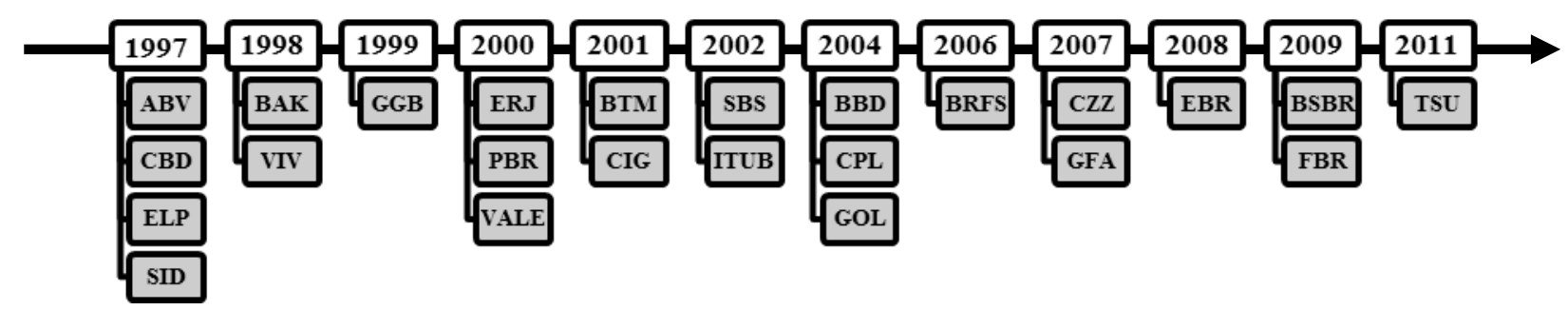

Fonte: Dados da pesquisa.

Para a BM\&FBOVESPA, no que diz respeito aos setores em que as empresas estudadas atuam, constatou-se que há uma grande quantidade de setores que estão procurando recursos fora do país, uma vez que dos 10 setores existentes na classificação da bolsa brasileira apenas os setores de Tecnologia da Informação e Consumo Cíclico não estão representados. Não havendo para tanto um setor que mais demanda captação de recursos externos do que outros. Os segmentos que mais se destacaram foram o de Energia Elétrica, com quatro empresas (Eletrobrás, CEMIG, CPFL e COPEL), e o de Bancos, com três empresas (Itaú Unibanco, Santander e Bradesco), que atuam nessa bolsa. Para Assaf Neto (2006), a captação de recursos no exterior é permeada pela maior rapidez nas operações, gerando uma maior liquidez.

Como relatado, a BMF\&BOVESPA possui três níveis de Governança Corporativa, visando uma maior transparência e no combate a algumas questões, tal como o problema de agência. Ao analisar o nível de Governança Corporativa das empresas brasileiras listadas na NYSE, verifica-se que há empresas listadas nos três níveis, assim como há empresas que não possuem níveis. No nível 1 encontram-se a maioria das empresas, 42\%, em segundo lugar aparece o Novo Mercado com 29\% das empresas listadas, ainda cerca de $17 \%$ das empresas não estão em nenhum nível de governança da bolsa brasileira. Segundo Neto e Famá (2001), esses níveis, juntamente com a estabilização da economia e um maior acesso ao capital estrangeiro proporcionam um maior crescimento da bolsa de valores. Silva (2007) complementa ao enfatizar que a entrada de empresas que possuem níveis de Governança diferentes, proporciona o desenvolvimento de um ambiente de negociação que estimula tanto os interesses de investidores quanto à própria valoração dessas empresas.

\section{PRÁTICAS DE GOVERNANÇA CORPORATIVA E EXIGÊNCIAS NORTE-AMERICANAS}

Para que as companhias não americanas atuem na NYSE, elas devem seguir um número reduzido de normas relacionadas à governança corporativa dispostas pela NYSE, aprovada em 2003 pela Securities and Exchange Commission dos EUA ("SEC"). Dentre essas normas, as empresas estrangeiras devem 
realizar uma análise comparativa entre as práticas de governança corporativas adotadas pela organização e as regras exigidas pela NYSE. Assim como primeiro aspecto de comparação, as companhias que estão listadas na NYSE devem apresentar a maioria dos membros de seu conselho de administração independentes. As atribuições do conselho de administração são, de acordo com Gondrige, Clemente, Espejo (2012, p. 74), "a definição da estratégia, a eleição e destituição do executivo principal (CEO), a aprovação da escolha ou da dispensa dos demais executivos por proposta do $C E O$, o acompanhamento da gestão e o monitoramento dos riscos". Esses autores enfatizam também que vários estudos comprovaram que conselhos mais independentes possuem decisões mais direcionadas aos interesses dos acionistas.

Das empresas listadas, verifica-se que apenas 4 delas seguem essas normas, sendo essas a COPEL, a GAFISA, a CSN e a TELEFÔNICA. De acordo com os resultados apresentados pelos estudos de Wagner, Stimpert e Fubara (1998) apud Andrade et al (2009), é necessário que os conselhos de administração possuam uma quantidade equilibrada de administradores independentes, já que esses tendem a apresentar melhores resultados para a organização. Ressalta-se que apesar de essas empresas seguirem essas normas da NYSE, não há nenhuma lei brasileira que se assemelha a essas exigências, o que caracteriza mais de $83 \%$ das empresas não as seguirem, sendo que a própria NYSE não obriga empresas controladas ${ }^{4}$ a cumprir com essa exigência, se encaixando nesse quesito a AMBEV, BRASIL TELECOM, BRASKEM, CEMIG, COPEL, CPFL, PETROBRÁS e VALE.

No Brasil, as principais exigências quanto ao conselho independente são, de acordo com as normas de Governança Corporativa da BM\&FBOVESPA, no Nível 1, as empresas precisam possuir apenas um conselho composto, no mínimo, por três membros, sendo que não é exigido a presença de conselheiros independentes. Já para o Nível 2 e para o Novo Mercado, é exigido que as empresas listadas possuam um conselho composto por cinco membros, sendo que deve haver, no mínimo, $20 \%$ dos diretores independentes, de acordo com os termos definidos nos regulamentos.

Outra norma referente às empresas listadas na NYSE se refere à de que os membros do Conselho de Administração, que não referem-se a diretores de uma das empresas, devem reunir-se regularmente sem que haja a presença dos membros referentes à diretoria. Esses conselheiros não executivos, segundo Andrade e Rosseti (2001) apud Dias (2010) baseado no relatório de Cadbury, estão sujeitos a realizar julgamentos independentes sobre a estratégia, o desempenho, a alocação dos recursos e os padrões de conduta da organização, devendo ser eleitos por mandatos determinados e por processo formal.

De acordo com os dados, infere-se que 9 das empresas se apresentam em seus relatórios como cumpridoras dessa norma, enquanto que as demais não a seguem, por não ser uma norma determinada pela Lei das Sociedades Anônimas (S/A) no Brasil, sendo que esta Lei determina apenas que até $1 / 3$ dos membros do conselho de administração pode ser eleito para cargos gerenciais, sendo que para tanto, os outros membros do conselho que não estão relacionados à gestão também não possuem autonomia para gerenciar essas organizações.

Ademais, a NYSE determina também que as empresas norte-americanas devem dispor de um comitê de nomeação/governança corporativa, formado exclusivamente por conselheiros independentes, dispondo de um regimento interno que detenha certos deveres mínimos. Para essa norma, companhias controladas não estão sujeitas a cumprir com essas exigências, sendo essas a AMBEV, BRASIL TELECOM, BRASKEM, CEMIG, COPEL, CPFL, PETROBRÁS e VALE.

Das demais empresas, 4 seguem essa norma, segundo os dados disponibilizados por elas em seus relatórios, sendo que o restante, 12 empresas, a maioria, enfatizam que a Legislação das S/A não obriga a

\footnotetext{
${ }^{4}$ Companhias controladas, conforme a Lei das Sociedades Anônimas são aquelas em que a controladora detém, direta ou indiretamente, os direitos de sócio que lhe garantem poder de eleger a maioria dos administradores, bem como a superioridade nas deliberações sociais.
} 
manter esses comitês e nem há restrição com relação à constituição de membros independentes, logo por esse motivo não possuem a exigência de a seguir, pois não há lei brasileira que a determine.

Dentre as regras que devem ser observadas pelas emissoras privadas não americanas está também existência de um comitê de remuneração que deve ser composto em sua plenitude por conselheiros independentes, pautados por um regimento interno que especifique seus deveres mínimos (NYSE, 2013). Como aponta Barbosa (2012), tais comitês nos EUA passaram a ser uma exigência em resposta a crise de 2008, como prevenção aos possíveis riscos de mercado e para disseminar a transparência de gestão. O mesmo autor complementa que, no Brasil a ideia de um comitê de remuneração foi implementada via Resolução do Conselho Monetário Nacional (CMN) em 2010.

Assim, o comitê de remuneração (de compensação ou de Recursos Humanos, como também é conhecido) tem por premissa proporcionar maior valor aos acionistas, empregados, fornecedores, clientes, investidores, governo e sociedade ao alinhar as políticas de remuneração das empresas com a gestão de riscos, o controle e a transparência. Desta forma se busca uma proteção institucional e a proteção contra práticas inadequadas de governança corporativa (BARBOSA, 2012).

Embora algumas empresas brasileiras listadas na NSYE que por serem classificadas como companhias controladas não possuem como exigência pela lei norte-americana à formação de um comitê de remuneração, esse último é constituído por elas no intuito de obter mais adequabilidade à lei, bem como de proporcionar maiores mecanismos de governança. Essas companhias controladas junto de outras que não tem a obrigatoriedade do comitê conforme disposição da lei brasileira, mas que da mesma forma o instituíram, representam 9 empresas e todas as companhias brasileiras presentes na NYSE, sendo elas a GPA, CPFL, FIBRIA, PETROBRAS, VALE, GAFISA, GERDAU, GOL e TIM.

Como aponta Oda (2009), os comitês de remuneração ganharam destaque nas agendas de governança corporativa das organizações, principalmente em virtude da premissa de que incentivos insuficientes podem tornar improdutiva a atividade dos agentes/administradores, assim como incentivos em excesso, quando mais relacionados a desempenho do que a risco, podem induzir comportamentos impróprios. É importante destacar que as demais empresas brasileiras listadas na NSYE atribuem ao conselho de administração as responsabilidades da remuneração, mas expõe que essas são votadas pelos acionistas.

Outro requisito a ser preenchido pelas empresas brasileiras concerne à constituição de um comitê de auditoria, formado por no mínimo três conselheiros independentes regidos por um regulamento interno que especifique os deveres mínimos (NYSE, 2013). Tal comitê tem como função, segundo o instituto Brasileiro de Governança Corporativa de 2009, a operacionalização dos deveres e responsabilidades da função de supervisão da gestão dos processos internos e assegurar a integridade e efetividade dos controles internos para a produção de relatórios financeiros, visando proteger interesses de acionistas e partes interessadas. Assim o comitê de auditoria surge na governança corporativa com o intuito de oferecer suporte ao conselho de administração em questões que tangem a auditoria, contabilidade e finanças almejando a transparência das informações e a prestação de contas dos administradores (OLIVEIRA; COSTA, 2005).

Os autores supracitados complementam que a constituição desse comitê ganhou centralidade no cenário mundial em virtude da lei americana, Lei Sarbanes-Oxley, em 2002, que exige o comitê das companhias estrangeiras e nacionais. Oliveira e Costa (2005) expõem ainda que, mesmo que a lei americana tenha aberto exceções às empresas estrangeiras, a determinação do comitê é considera pelos principais códigos de governança corporativa, pelos investidores e pelo mercado como um principais códigos de governança corporativa, pelos investidores e pelo mercado como um instrumento que fortalece a governança corporativa das empresas. 
Diante do exposto, tem-se que 13 das empresas brasileiras listadas na NSYE exercem a prerrogativa da isenção e não tem em sua composição o comitê de auditoria, nessas empresas há a presença de um comitê fiscal, ou mesmo o conselho de administração, que exerce algumas atribuições adicionais de comitê de auditoria. Esse comitê fiscal com funções adicionais também é conhecido como comitê fiscal turbinado (SOUZA, 2010). Entretanto, o Instituto Brasileiro de Governança Corporativa (2009) em seu guia de orientação para as melhores práticas reitera que a opção pelo comitê fiscal turbinado só pode ser utilizada pelas companhias para fins das exigências instituídas perante à SEC, sendo inadequada essa atribuição do conselho de auditoria ao conselho fiscal em qualquer outra situação. As demais companhias implementaram comitês exclusivos de auditoria, sendo em alguns casos não são compostos totalmente por membros independentes à empresa, direito que é permitido pela lei vigente brasileira.

Além disso, a legislação norte-americana também determina que as companhias listadas deverão permitir que todos os acionistas votem sobre todos os planos de remuneração mediante oferta de participação no capital da companhia, bem como as alterações dos mesmos, levadas em consideração algumas exceções constantes das regras da NYSE (NYSE, 2013). Desse modo, tem-se que 6 das companhias brasileiras listadas deixam explícito que não possuem planos de remuneração e por esse motivo a aprovação dos acionistas não se faz necessário. Outras 12 companhias expõem que seguem a Lei das Sociedades Anônimas brasileira que exige a pré-aprovação dos acionistas para a adoção e revisão de quaisquer planos de remuneração do capital e 2 não deixam claro em seus documentos qual a práticas adotadas.

Por fim, neste critério, empresas como a Cosan Limited, GPA, Brasil Telecom e Santander Brasil, assumem conduta diferente daquelas assumidas pelas demais. O Santander, por exemplo, expõe que os acionistas do Banco não têm a oportunidade de votar todos os planos de remuneração por ações, por sua vez, a Brasil Telecom e a GPA apresentam que tal aprovação dos acionistas foi delegada ao conselho de administração, como é permitido pela Lei das Sociedades Anônimas. Ademais a Cosan Limited, empresa brasileira, mas que tem sede nas Bermudas, afirma que nesse país a aprovação dos acionistas não é necessária.

Para cumprir mais uma exigência da NSYE as companhias estrangeiras listadas devem adotar e divulgar diretrizes de governança corporativa que compreendam certos requisitos mínimos estabelecidos pela bolsa, abordando aspectos como as responsabilidades do diretor presidente e a disponibilização de práticas de governança em seus websites (NYSE, 2013). Nesse sentido, como expõe Lethbridge (1997), os investidores exercem cada vez mais pressão para que se tenha determinadas normas de transparência nas ações das companhias.

Assim, das 24 empresas brasileiras listadas todas mencionam seguir a legislação brasileira ao que tange as exigências de mecanismos de governança corporativa e, a maioria, se enquadra em algum nível de governança estabelecido pela bolsa brasileira. Tais mecanismos utilizados pelas empresas, segundo elas próprias, não abrangem todos os pontos descritos nas normas norte-americanas. Segundo Fernandes et al. (2012), a principal dificuldade das empresas em adotar práticas de governança corporativa está no rompimento do modelo tradicional de gestão e na dificuldade em se adequar aos mecanismos criados para assegurar a transparência. Os mesmos autores apontam que a dificuldade de prestar contas é uma questão frequentemente presente no cotidiano das companhias.

Do mesmo modo, a NYSE dispõe também que as companhias devam adotar e divulgar um código de conduta e ética para conselheiros, diretores e empregados, e divulgar qualquer exceção que esse venha a conter (NYSE, 2013). O código de conduta tem a função de traçar diretrizes claras e fomentar o diálogo sempre que ocorrerem situações ambíguas e tem a função de padronizar e formalizar os relacionamentos e 
operações da organização com seus diversos públicos (SILVA, 2007).

Ainda que não haja na lei brasileira exigência semelhante todas as companhias analisadas cumprem tal requisito. Dentre as tendências que influenciam a importância dos códigos de conduta e de ética e que desse modo influenciam também a sua adesão pelas empresas, destaca-se, de acordo com Berenbeim (2000) apud Silva (2007): a globalização dos mercados que exige que as empresas tenham tais códigos como forma de pronunciarem seus princípios diante de suas operações; o crescimento de práticas de governança e a participação dos conselhos de administração na elaboração destes códigos de conduta e de ética e o aumento do conhecimento, por parte dos gestores, de temáticas relacionadas à ética, o que é refletido em códigos cada vez mais robustos

Por fim, a última regra de governança da NSYE concerne à determinação de que o CEO das companhias listadas devem declarar a cada ano à bolsa americana que não tem conhecimento de infrações cometidas pela companhia contra as regras de governança corporativa da NYSE para companhias listadas (NYSE, 2013).

Nesse critério, 14 empresas afirmam que os seus respectivos CEOs cumprirão com a exigência de declarações anuais. As demais companhias (TIM, FIBRIA, EMBRAER, SABESP, GPA, ELETROBRÁS, BR FOODS, BRASKEM, BRASIL TELECOM E SANTANDER BRASIL) não mencionam em seu relatório como procedem em relação à regra em questão.

O quadro 4, sintetiza a comparação entre as exigências brasileiras e as exigências da NYSE no que tange as empresas estrangeiras listadas nessa bolsa.

Quadro 4: Comparação de Exigências, EUA e Brasil.

\begin{tabular}{|c|c|}
\hline \multicolumn{2}{|c|}{ Comparação das Práticas de Governança Corporativa exigidas nos EUA e no Brasil } \\
\hline Estados Unidos da América & Brasil \\
\hline Conselhos Independentes. & $\begin{array}{c}20 \% \text { de conselheiros independentes para o mercado } \\
\text { nível 2 e para o novo mercado. }\end{array}$ \\
\hline Sessões Executivas. & Não à exigência de comitê de Sessões Executivas. \\
\hline Comitê de Governança Corporativa. & Não à exigência de comitê de Governança Corporativa. \\
\hline Comitê de Remuneração. & Não à exigência de Comitê de Remuneração. \\
\hline Comitê de Auditória. & Não à exigência de Comitê de Auditoria. \\
\hline Planos de Remuneração por Ações. & $\begin{array}{c}\text { Não à exigência de Planos de Remuneração por ações } \\
\text { pela lei das S/A's no Brasil. }\end{array}$ \\
\hline Diretrizes de Governança. & $\begin{array}{c}\text { Com relação as diretrizes de Governança, as empresas } \\
\text { brasileiras devem seguir as normais tangentes ao seu } \\
\text { nível de governança na BM\&FBOVESPA. }\end{array}$ \\
\hline Código de Ética. & Não à exigência de Código de Ética. \\
\hline Declaração de não violação a regras da NYSE. & Não à exigência de envio de declaração para esses fins. \\
\hline
\end{tabular}

Fonte: Elaborado pelos autores, dados NYSE e BM\&FBOVESPA.

\section{CONSIDERAÇÕES FINAIS}

O fenômeno de globalização econômica ocorrido nas últimas décadas se tornou uma mola propulsora para um processo mais recente, a globalização financeira, que pode ser caracterizada pela interligação de mercados de capitais de diversos países, visando a uma melhor fonte e aplicação de recursos no âmbito mundial. Nesse sentido, para que as empresas possam usufruir dessa nova perspectiva, o desenvolvimento de práticas de governança corporativa se faz necessário e vem se consolidando. Assim, o movimento crescente de companhias brasileiras atuando na NYSE e as exigências sobre governança corporativa do mercado norte-americano para com empresas estrangeiras foram os aspectos motivadores para o presente artigo. 
Identificou-se que, nos últimos anos, diversas empresas passaram a listar suas ações na bolsa norte-americana, caracterizada por um mercado com maior liquidez e que incentiva a entrada de companhias estrangeiras. Ademais, dentre 24 empresas analisadas, constatou-se que elas representam diversos setores, contrapondo os estudos de Medeiros e Tibério (2009) e Pagano et al. (2001), que destacaram que apenas alguns setores, como o de alta tecnologia e de empresas exportadoras, apresentam maior potencial de atuarem no exterior. Além disso, o fato das companhias atenderem níveis de governança mais altos na BM\&FBOVESPA, não é determinante para que as empresas atuem na NYSE, uma vez que verificou-se uma dispersão da amostra selecionada entre todos os níveis diferenciados de governança corporativa da BM\&FBOVESPA apresentados pela bolsa brasileira.

As exigências em relação a comitês de nomeação e de remuneração, membros independentes no conselho de administração, necessidade de reuniões do conselho de administração sem os membros da diretoria, estabelecimento de planos de remuneração e estabelecimento de diretrizes gerais de governança corporativa apresentaram um percentual de empresas que as realizam inferior a 50\%, fato justificado, na maioria das vezes pela não exigência da legislação brasileira ou pela exceção concedida a empresas controladas. Além disso, destaca-se que $46 \%$ das empresas estudadas omitiram em seu relatório o posicionamento da empresa quando ao fator de envio de declarações anuais dos diretores presidentes à NYSE, informando sobre a não violação da bolsa norte-americana.

Em contrapartida, todas as companhias afirmaram possuir um código de conduta e ética, o que reitera a importância desse requisito para a visibilidade das empresas atualmente. A exigência de um comitê de autoria nas companhias foi outro fator que se destacou, pois quase metade das empresas estudadas, 46\%, afirmou possuí-lo, mesmo não sendo uma exigência da regulamentação brasileira. As demais empresas, mesmo não possuindo um comitê específico de auditoria, possuem um comitê fiscal turbinado, se enquadrando na exceção permitida pela norma norte-americana. Assim, ressalta-se que as companhias estão bem posicionadas em relação ao aspecto de auditoria, sendo esse um dos instrumentos mais importantes dentro do âmbito das práticas de governança corporativa.

Por tudo isso, referenda-se que os objetivos propostos nesse artigo foram atingidos e como principais contribuições, destaca-se que as companhias brasileiras estudadas, diante desse fenômeno de globalização financeira, se posicionam positivamente perante às normas de governança corporativa da NYSE para as empresas norte-americanas, uma vez que, a maioria dos aspectos considerados não é uma exigência brasileira. Nesse sentido, considerando como limitação da pesquisa a análise apenas das empresas listadas na NYSE, sugere-se novos estudos que avaliem um grupo mais abrangente de empresas e que adotem uma abordagem de análise mais aprofundada, com a coleta de dados primários, para referendar ou refutar as conclusões obtidas, agregando ao arcabouço teórico-empírico da área.

\section{REFERÊNCIAS}

ANDRADE, G. A. R. ANDRADE, A. R. Governança Corporativa - Estudos de Escândalos Corporativos no Brasil e no Mundo. Simpósio de excelência em gestão e tecnologia. 2005.

ANDRADE, L.P.de et al. Governança corporativa: uma análise da relação do conselho de administração com o valor de mercado e desempenho das empresas Brasileiras. Rev. Adm. Mackenzie (Online), São Paulo, v. 10, n. 4, Aug. 2009.

ANDRADE, A.; ROSSETTI, J.P. Governança corporativa: Fundamentos, desenvolvimento e tendências. 2 ed. São Paulo: Atlas, 2006.

ASSAF NETO, A. Finanças corporativas e valor. 2. ed. São Paulo: Atlas, 2006. 
BARBOSA, D. C. Contabilidade Criativa: Um Estudo Sobre o Papel do Comitê de Remuneração nas Instituições Financeiras. 2012. 24f. Monografia (Graduação em Ciências Contábeis) - Faculdade de Tecnologia e Ciências Sociais Aplicadas, Centro Universitário de Brasília.

BASSO, G. G. Governança corporativa no Brasil: o impacto da adesão à câmara de arbitragem do mercado no risco de empresas de capital aberto. Brasília, 2011.

BM\&FBOVESPA. Visão geral, governança corporativa . Disponível em: < http://ri.bmfbovespa.com.br/static/ptb/visao-geral.asp?idioma=ptb>. Acesso em: 13 mai. 2014.

BORGERTH, V. M. da C. SOX Entendendo a Lei Sarbanes-Oxley: um caminho para a informação transparente. Cengage Learning, 2011.

CARVALHO, A. G. Governança corporativa no Brasil em perspectiva. Revista de Administração e Contabilidade. São Paulo, 2002.

COLOMBO, J. A.; GALLI, O. C. Governança corporativa no Brasil: níveis de governança e rendimentos anormais. Revista Portuguesa e Brasileira de Gestão. 2010.

CORREIA, L. F. A.; FERNANDES, H.; LOUVET, P. Um índice de avaliação da qualidade da governança corporativa no Brasil. R. Cont. Fin. - USP, São Paulo, v. 22, n. 55, p. 45-63, jan./fev./mar./abr. 2011

DIAS, R. Influências de práticas de governança corporativa sobre as decisões de estrutura de capital de companhias brasileiras. 2010. Monografia em Bacharel em Ciências Econômicas. Universidade Federal do Rio Grande do Sul. Porto Alegre.

ESCAVASSA, K. M. Mercado acionário: o crescimento da participação de pessoas físicas na bolsa de valores na década de 2000. Revista das Faculdades Integradas Claretianas, v.1, jan./dez., 2008.

FERNANDES, F.C.et al. Evidenciação obrigatória de hedge accounting em companhias abertas listadas no índice de sustentabilidade empresarial (ISE). XIV ENGEMA - ENCONTRO NACIONAL SOBRE GESTÃO EMPRESARIAL E MEIO AMBIENTE, São Paulo, 2012.

FURLAN, F. Bolsa brasileira ganha só do Chipre e da Jamaica. 2013. Valor Econômico. Disponível em: http://brasileconomico.ig.com.br/ultimas-noticias/bolsa-brasileira-ganha-so-do-chipre-e-dajamaica_130258.html. Acesso em 10 jun. 2014.

GARCIA, F. A. Governança Corporativa. 2005. Monografia, Instituto de economia, Universidade Federal do Rio de Janeiro.

GONDRIGE, E. de O.; CLEMENTE, A.; ESPEJO, M. M. dos S. B.. Estrutura do conselho de administração e valor das companhias brasileiras. BBR, Vitória, v. 9, n. 3, Art. 4, p. 72 - 95, jul.-set. 2012.

GONÇALVES, et. al. Social Disclosure das empresas brasileiras listadas na NYSE e na BOVESPA: sua relação com os níveis de governança corporativa. Revista Contemporânea de Contabilidade, 2008.

IBGC - INSTITUTO BRASILEIRO DE GOVERNANÇA CORPORATIVA. Governança Corporativa. Disponível em: < http://www.ibgc.org.br/index.php> . Acesso em: 20 maio 2014.

Guia de orientação para melhores práticas de comitês de auditoria. Instituto Brasileiro de Governança Corporativa, 2009. Disponível em: < http://www.ibgc.org.br/CadernoGovernanca.aspx?CodCaderno=53> Acesso em: 14 jun. 2014.

JENSEN, M.; MECKLING, W. Theory of the firm: managerial behavior, agency costs and ownership structure. Journal of Financial Economics, v.3, n.4, p.305-360, 1976. 
JÚNIOR, A. S. Brasil é 'estrangeiro' com mais negócios na Nyse. 2012. Estadão. Disponível em: http://www.estadao.com.br/noticias/impresso,brasil-e-estrangeiro-com-mais-negocios-nanyse, $958398,0 . \mathrm{htm}$. Acesso em: 15 maio 2014.

LETHBRIDGE, E. Governança Corporativa. 1997. Disponível em: < http://www.bndes.gov.br/SiteBNDES/export/sites/default/bndes_pt/Galerias/Arquivos/conhecimento/revis ta/rev809.pdf> Acesso em: 14 jun. 2014.

LISOT, A. Os princípios da Governança Corporativa no processo de modernização da gestão da segurança pública no Brasil. Revista de Ordem Pública. 2012.

MEDEIROS, O. R. de; TIBÉRIO, C. S. B. Fatores que influenciam as empresas brasileiras na decisão de listar suas ações em bolsas de valores estrangeiras. BASE. v. 6 - n. $2 \cdot$ maio/ago. 2009.

MERAT, Carolina dos Santos. Empresas de capital aberto: Mudanças após Lei SOX. 2011. Dissertação (Mestrado), Universidade Candido Mendes. Rio de Janeiro.

MOTTA, J. L. S.; SILVEIRA, A. M.; BORGES, L. F. X. Exemplo de Modelo Referencial de Governança Corporativa. Revista do BNDES. 2006.

NETO, R. M. R.; FAMÁ, R. Uma alternativa de crescimento para o mercado de capitais brasileiro: o novo mercado. SEMEAD, 2001.

NEVES, J. L. Pesquisa Qualitativa: Características, usos e possibilidades. Cadernos de Pesquisa em Administração. São Paulo, v.1, n. 3, ago-dez, 1996.

NYSE - BOLSA DE VALORES DE NOVA YORK. Listed Company Manual. 2013. Disponível em: < http://nysemanual.nyse.com/LCM/> . Acesso em: 13 jun. 2014.

ODA, P. Por que a sua companhia não possui um comitê de remuneração? . 2009. Disponível em: < http://www.capitalaberto.com.br/temas/por-que-a-sua-companhia-nao-possui-um-comite-deremuneracao/\#.U5zOWvldVrR> Acesso em: 14 jun. 2014

OLIVEIRA, M. C.; COSTA, P. P. O Comitê de Auditoria nas Companhias Abertas Brasileiras: Um Estudo Multicaso. Anais do $5^{\circ}$ Congresso USP de Controladoria e Contabilidade, São Paulo, 2005. Disponível em: http://www.congressousp.fipecafi.org/ Acesso em: 14 jun. 2014.

OLIVEIRA, V. A., LEMES, S. Nível de convergência dos princípios contábeis brasileiros e norteamericanos às normas do IASB: uma contribuição para a adoção das IFRS por empresas brasileiras. $\mathbf{R}$. Cont. Fin. - USP, São Paulo, v. 22, n. 56, p. 155-173, maio/jun./jul./ago. 2011.

PAGANO, M.et al.What Makes Stock Exchanges Succeed? Evidence from Stock Listing Decisions, European Economic Review, v.45, n.4-6, p. 770-782. 2001.

PEREIRA, D. Porque a nossa bolsa de valores é tão volátil? 2012. Disponível em: http://www.administradores.com.br/artigos/economia-e-financas/porque-a-nossa-bolsa-de-valores-e-taovolatil/61527/. Acessado em: 10 jun. 2014.

PITZER, A. A influência do nível de governança corporativa no valor de mercado das ações das empresas brasileiras negociadas na BOVESPA.2011. Dissertação (Mestrado em Administração e Desenvolvimento Empresarial). Universidade Estácio de Sá, Rio de Janeiro.

PLIHON, M. A globalização financeira. Colóquio Pobreza, Dívida Externa e as Três Instituições Irmãs: FMI, Banco Mundial e OMC. Faculdade de Economia, Universidade de Coimbra, 19 e 20 abr. 2007.

RODRIGUES. A. T. L. Governança Corporativa: Quando a Transparência passa a ser uma exigência global. In: CONVENÇÃO DE CONTABILIDADE DO RIO GRANDE DO SUL, 9. Anais... 2003. 
SANTOS, A. G. Comitê de Auditoria: Uma análise baseada na divulgação das informações de empresas brasileiras. 2009. Dissertação ( Mestrado).Universidade de São Paulo.

SILVA, V. G. DA. O uso do código de conduta ética como instrumento de controle gerencial em empresas internacionalizadas. 2007. 103f. Dissertação (Mestrado em Ciências Contábeis) - Faculdade de Administração e Finanças, Universidade do Rio de Janeiro.

SILVA, M.; SANTOS, F. T. Evidenciação de Práticas de Programas de Remuneração por Ações pelas Companhias Listadas no Novo Mercado da Bolsa de Valores de São Paulo - Bovespa. R. Cont. UFBA. 2009.

SOUZA, P. C. S. S. Práticas do Comitê de Auditoria: Evidências de Empresas Brasileiras. 131f. 2010. Dissertação (Mestrado em Ciências Contábeis) - Faculdade de Economia, Administração e Contabilidade, Universidade de São Paulo,.

SROUR, G. Práticas diferenciadas de governança corporativa: um estudo sobre a conduta e a performance das firmas brasileiras. Revista Brasileira de Economia. 2005.

VIEIRA, M. M. F. Por uma boa pesquisa (qualitativa) em administração. In: VIEIRA, M.M.F.; ZOUAIN, D.M. (Org.) Pesquisa Qualitativa em Administração. Rio de Janeiro: FGV, p.13-28, 2006. 
